\title{
Design and development of intelligent electronic tutorial software for GSM maintenance in Nigeria
}

\author{
Ekwonwune Emmanuel Nwabueze ${ }^{1 *}$, Nwachukwu Catherine Ada Ngozi ${ }^{2}$, Anyaduba Obiageli J. $^{3}$, Obikwere Fortune $^{4}$ \\ ${ }^{1}$ Department of Computer Science, Imo State University, Owerri, Nigeria \\ ${ }^{2}$ Department of Computer Science, Federal Polytechnic, Nekede, Owerri, Imo State, Nigeria \\ ${ }^{3}$ ICT Department, Alvan Ikoku Federal College of Education, Owerri, Imo State, Nigeria \\ ${ }^{4}$ Liturgy Communications Limited, Owerri, Nigeria \\ *Corresponding author E-mail: ekwonwuneemmanuel@yahoo.com
}

Copyright ( $\odot 2015$ Ekwonwune Emmanuel Nwabueze et al. This is an open access article distributed under the Creative Commons Attribution License, which permits unrestricted use, distribution, and reproduction in any medium, provided the original work is properly cited.

\begin{abstract}
The Global System of Mobile communication (GSM) technology has permeated every facet of human existence ,that man can no longer do away with it. This piece of work was motivated by the nagging problems, which include poor quality of service by telecom service providers, which attempts to negate the value of this revolution, inaccurate and interrupted service delivery which have resulted to delayed and aborted calls, traffic congestion, low bandwidth and oversubscription errors, inter alia. So the primary objective of this article therefore, is to design and develop intelligent electronic tutorial GSM software that would be capable of providing relevant answers to some GSM-based service challenges raised above. The Structured Systems Analysis and Design Methodology (SSADM) was employed as research methodology. The expected results shall include, among others, broadened scope of knowledge in GSM tutorial software engineering, provision of user friendly environment and cost effective communication system for a happy customer and a better society; provide an effective and feasible solution for a reliable and accurate GSM management system that would improve the efficiency and productivity of Nigerian information and communication infrastructure.
\end{abstract}

Keywords: Software; Tutorial; Desig; Communications; Telecommunications; GSM; Technology.

\section{Introduction}

According to TelecomSpace [1], Global system for mobile communication (GSM) is a globally accepted standard for digital cellular communication. It affirms that GSM is the name of a standardization group established in 1982 to create a common European mobile telephone standard that would formulate specifications for a pan-European mobile cellular radio system operating at $900 \mathrm{MHz}$. Telecom Space posits that it was estimated that many countries outside of Europe would join the GSM partnership in due course (as being experienced in Nigeria today). She maintained that Cellular (which refers to a range of technology solutions that may be used to deliver GSM services) is one of the fastest growing and most demanding telecommunications applications. This view was supported by MobileCommunication.com [2], which added that GSM uses a variation of Time Division Multiple Access (TDMA) and is the most widely used of the three digital wireless telephony technologies namely: TDMA, GSM, and CDMA. GSM digitizes and compresses data, then sends it down a channel with two other streams of user data, each in its own time slot that operates at either the 900 $\mathrm{MHz}$ or $1800 \mathrm{MHz}$ frequency band.

According to GSM World [3], there are now more than 2 billion GSM mobile phone users worldwide. GSM World references China as "the largest single GSM market, with more than 370 million users, followed by Russia with 145 million, India with 83 million and the USA with 78 million users." Since many GSM network operators have roaming agreements with foreign operators, users can often continue to use their mobile phones when they travel to other countries. SIM cards (Subscriber Identity Module) holding home network access configurations may be switched to those with metered local access, significantly reducing roaming costs while experiencing no reductions in service. 
GSM, together with other technologies, are parts of the evolution of wireless mobile telecommunications that include: High-Speed Circuit-Switched Data (HSCSD), General Packet Radio System (GPRS), Enhanced Data GSM Environment (EDGE), and Universal Mobile Telecommunications Service (UMTS).

Nonetheless, throughout the evolution of cellular telecommunications, various systems have been developed without the benefit of standardized specifications, which presented many problems directly related to compatibility, especially with the development of digital radio technology. The GSM standard is intended to address these problems. GSM provides recommendations, not requirements. The GSM specifications define the functions and interface requirements in detail but do not address the hardware. The reason for this is to limit the designers as little as possible but still to make it possible for the operators to buy equipment from different suppliers. GSM World maintained that the GSM network is divided into three major systems: the Switching System (SS), the Base Station System (BSS), and the Operation and Support System (OSS).

Radio eclectronic.com [4] maintained that one of the basic aims of GSM technology was to provide a system that would enable greater capacity to be achieved than the previous first generation analogue systems. GSM achieved this by using a digital TDMA (time division multiple access approach). By adopting this technique more users could be accommodated within the available bandwidth. In addition to this, ciphering of the digitally encoded speech was adopted to retain privacy. Using the earlier analogue cellular technologies, it was possible for anyone with a scanner receiver to listen to calls and a number of famous personalities had been "eavesdropped" with embarrassing consequences.

Radio eclectronic.com [4] enumerated the services of GSM as follows: 'Speech or voice calls are obviously the primary function for the GSM cellular system. To achieve this, the speech is digitally encoded and later decoded using a vocoder. A variety of Vocoders are available for use, being aimed at different scenarios. In addition to the voice services, GSM cellular technology supports a variety of other data services. According to Radio eclectronic.com, [4] one service that has grown enormously is the short message service. Developed as part of the GSM specification, it has also been incorporated into other cellular technologies. It can be thought of as being similar to the paging service but is far more comprehensive allowing bi-directional messaging, store and forward delivery, and it also allows alphanumeric messages of a reasonable length. This service has become particularly popular, initially with the young as it provided a simple, low fixed cost. It posits that GSM cellular technology had a number of design aims when the development started, that included offering good subjective speech quality, having a low phone or terminal cost, and terminals that could to be handheld.

\subsection{Conceptual framework}

Communication has become one of the basic desires of the modern man. Mobile phones since have been taken as part of our social life. Now virtually, every private resident in the city has a mobile phone. People in the rural communities also have access to it. Today, mobile networks in Nigeria have the fastest growth rate in the African continent according to National Communication Commission report, [5]. Since it's introduce in 2001, the industry has grown to an unimaginable success. Media reports indicate that the ownership of active lines is over 90 million. Not only has the industry the largest and fastest growing market in Africa, but it is also ranked as one of the ten topmost growing industries in the world with over 118 million Nigerian subscribers projected in 2014.

The coming into operations of Global System for Mobile (GSM) Communications has no doubt made life and living beautiful, easy, colourful, exciting and tenderly in the country with the deployment of latest technology in the field of information, communication and technology. There is no need for frequent visits to family and friends as one can converse daily with one's relatives everywhere they are on planet earth using GSM network. Beside telephone calls, text messaging, and multimedia services (MMS) which are provided by GSM operators; many of the players in the telecom sector also provide internet services through modems and subscription platforms including tele-video conferencing.

Conversely, the industry has witnessed many drawbacks. These include poor services of the operators and the weakness of the regulators to enforce quality compliance. Despite the claims of cutting edge technology, there is still high level of drop calls, cross connection where many calls are routed in error to GSM users different from the ones the caller wanted to call, for which the GSM operator still bills the subscriber and there is also network failures. None of the operators can lay claim to have effectively covered the country. It is on the basis of the above development i.e., the evolution, usage and contributions of GSM network to the Nigerian economy and the problems associated with it that this work finds its motivation. Therefore, exploring into intelligent software - based GSM tutorial that answers sum questions about the operations of this all important industry is most desirable at this point in time.

\subsection{Statement of the problem}

Since its inauguration in 2002, GSM services in Nigeria has been inundated with poor network signals, collection of money for non-committed voice and data services, over congestion, drop calls, delayed voice and data services and lack of adequate information or answers on why these inadequacies do occur. This is in addition to the theft of service by stealing the cell phone that houses the SIM card, invasion of privacy through hacking or cracking encrypted algorithms, 
unlawful interception of GSM communications by law enforcement agencies: this is generally done by accessing the digital switches that control calls. Majority of these problems have no proper explanation thereby leaving the customer confused and begging for answers.

\subsection{Objectives of the study}

This is to design and develop intelligent electronics tutorial software for GSM maintenance capable of:

i) Taking Frequently Asked Questions (FAQ) and provide answers to such questions.

ii) Use Control Message Services (CMS) to locate some content for study.

iii) Test the knowledge level acquired by the learner.

\subsection{Methodology}

Structured System Analysis and Design Methodology (SSADM) was used. According to Obichere [6], the justification for choosing SSADM over other engineering methods as approved by IEEE was its waterfall techniques through which systems designs are easily achieved. Both Logical Data Model (LDM), which is the process of identifying, modeling and documenting the data requirement of the new system to be designed and data are separated into entities and relationships and Data Flow Model (DFM), which is the process of identifying, modeling and documenting how data moves around in the system; examines the process, data storages, external entities and data flows in the entire system of SSADM were applied.

The materials used on the study included those gotten from field studies, primary and secondary sources of data and information and the World Wide Web, inter alia. Such materials included oral interviews, Newspaper and magazine articles, personal observations and internet search engines materials, among others. All these were integrated in an interwoven characteristic in order to make sense using the afore-mentioned research methodology to produce this work.

\subsection{The module tutorial software}

According to Encarter, the free encyclopedia [7], a tutorial is a method of transferring knowledge and may be used as a part of a learning process. More interactive and specific than a book or a lecture; a tutorial seeks to teach by example and supply the information to complete a certain task. Depending on the context, a tutorial can take one of many forms, ranging from a set of instructions to complete a task to an interactive problem solving session (usually in academia). In computer-based education, a tutorial is a computer program whose purpose is to assist users in learning how to use a software product such as an office suite or any other application, operating system interface, programming tool, or video game.

\subsection{System analysis and design}

\subsubsection{Analysis of the present system}

Investigation on the present system was carried out to obtain detailed fact about the application area to be designed. This was done by taking a look at the functional requirements of the present system and finding out whether the requirements of it are being achieved, identifying the constraints of the present system, looking at the range and volume of data processed, identifying the exceptional conditions and also noting its problems. To obtain these facts about the present system, several research methods were used.

a) Interviewing Of Personnel: This involved meeting the working staff, asking various questions and obtaining the answers from the staff GSM firms.

b) Observation: In the situation where answers to questions were not descriptive enough, it becomes necessary to observe the way things were being done, customer motivation and their reactions. For instance an ISP promotion on reduced call rates, cheaper modems and customer reaction to all these.

In his own view, Obichere [6] stated that the following were obtained from the investigation and analysis of the present system:

- Descriptions of the input and output documents,

- Description of organizational structure and

- Description of the present System.

Since the proposed aims to provide intelligent tutorial software based on FAQs on problems of GSM operations and usage in Nigeria, because for now, the GSM operation has no such intelligent software based maintenance tutorial to guide the usage and operation of the GSM information management system in modems like phones or internet. Meanwhile, such problems displayed as Frequently Asked Questions (FAQs) is as shown in a table format below. 
Table 1: Probable Problems, Causes and Solution of the Present System

\begin{tabular}{|c|c|c|}
\hline Problem Description & Possible Causes & Problem Solving \\
\hline $\begin{array}{l}\text { The system cannot run the } \\
\text { installation program } \\
\text { automatically }\end{array}$ & $\begin{array}{l}\text { The system configuration } \\
\text { is having difficulty with } \\
\text { the auto-run software. }\end{array}$ & $\begin{array}{l}\text { The device will appear as a virtual disc in 'My Computer' } \\
\text { on the PC's start menu. Click on the icon and start the } \\
\text { autorun.exe. If you have previously installed a version of } \\
\text { the program, please uninstall it first. }\end{array}$ \\
\hline $\begin{array}{l}\text { After installation, the } \\
\text { system doesn't install the } \\
\text { driver program properly. }\end{array}$ & $\begin{array}{l}\text { The system configuration } \\
\text { is having difficulty with } \\
\text { the auto-run software. }\end{array}$ & $\begin{array}{l}\text { Please install the driver program manually. The driver } \\
\text { program can be found in the installation folder; C: Program } \\
\text { Files } \backslash \text { Etisalat Nigeria \drivers }\end{array}$ \\
\hline $\begin{array}{l}\text { After the device is plugged } \\
\text { in, the UI program doesn't } \\
\text { run automatically. }\end{array}$ & $\begin{array}{l}\text { The system configuration } \\
\text { is incorrect. }\end{array}$ & $\begin{array}{l}\text { Please open the UI program manually. You can find it in } \\
\text { the Start menu: "C:Program menu or an alias icon on the } \\
\text { desktop. }\end{array}$ \\
\hline
\end{tabular}

Source: [6]

In the above, non-committed calls and messages, delayed services and short-changing of subscribers, call diverts, had been causes for concern. No proper software has been designed to answer the questions on why there existed the abovementioned anomalies, which were observed in the present GSM system. It should be noted that Lack of information regarding appropriate GSM maintenance tutorials, disruptions, and low accuracy of the connection schedules are to become worse within the context of expansions because customer complaints would only result in loss of interest, consequently resulting in public dissatisfaction and frustration leading to being mobile communication averse.

\subsection{Perceived problems with the present system}

i) Lack of services (signals) especially in the rural communities;

ii) Uncommitted but charged calls and data services leading to subscribers' complaint of being shortchanged;

iii) Over billing of subscribers through unsolicited promotional activities such as frequent call for subscription of music, health tips, and reduced calls rate and unsolicited messages;

iv) Poor equipment - transponders, transmitters, modems, handsets;

v) Interferences - signals, government, individuals, groups;

vi) No comprehensive tutorial software to address the above - mentioned complaints yet.

It is common belief that when the subscriber's questions are well answered, he will be able to appreciate the GSM services the more. The proposed work will provide answers in form of GSM FAQs intelligent maintenance tutorial. Conversely, the following are Perceived Bottlenecks to Efficient Operations of the Present System: Political issues, Government policies, financial constraints, Low bandwidth due to poor equipment, among others. The economic effects include:

- $\quad$ Lack of interest in GSM services due Poor signals, complaints here and there;

- $\quad$ Poor subscription rate

- $\quad$ Government loses revenue accruing from subscription tax and patronage

- Goodwill diminishes

- Low Gross Domestic Product, inter alia.

\section{8 .Proposed high level moel of the new system}




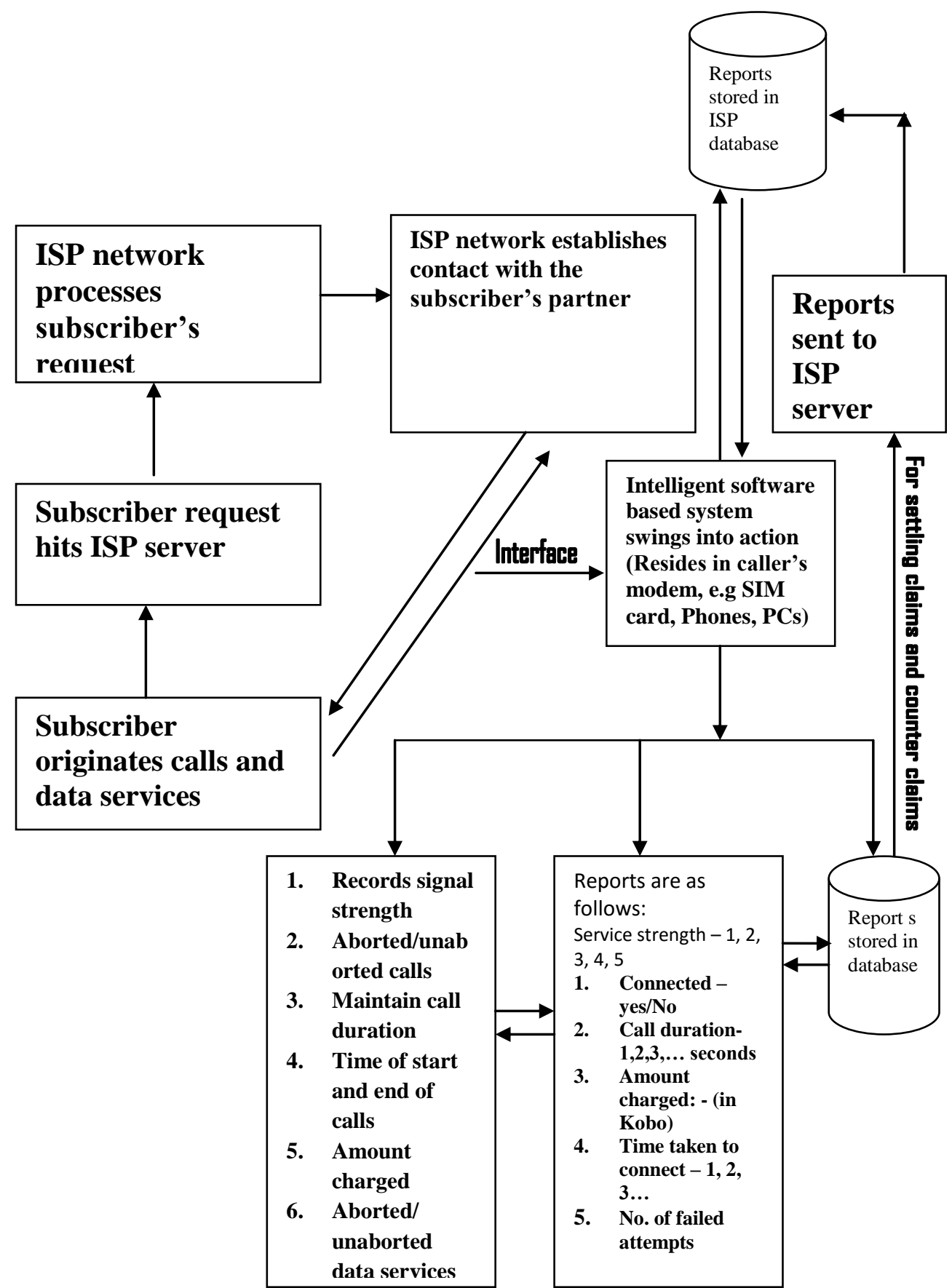

Fig. 1: Proposed High Level Model of New System: Source [6].

\section{Software design}

This is an investigative procedures and a stage involving detailing of how the system is to be built. It has to be detailed enough for the system to be fully implemented. During the design phase, the inputs are precisely defined as well as the required output. The database design is developed using Microsoft Access for storage of GSM Intelligent Tutorial Information system. Our Systems design in this work is the process that defines the architecture, components, modules, interfaces, and data for a system to satisfy specified requirements.

There is some overlap with the disciplines of systems analysis, systems architecture and systems engineering. Objectoriented analysis and design methods are the most widely used methods for computer systems design. The Unified Modeling Language (UML), which is the standard language in this object-oriented analysis and design. It is widely used for modeling software systems and is increasingly used for high designing non-software systems and organizations. There were also logical and physical designs used.

i) Logical design: The logical design of a system pertains to an abstract representation of the data flows, inputs and outputs of the system. This is often conducted via modeling, using an over-abstract (and sometimes graphical) 
model of the actual system. In the context of systems design are included. Logical design includes Entity Relationship Diagrams.

ii) Physical design: The physical design relates to the actual input and output processes of the system. This is laid down in terms of how data is input into a system, how it is verified / authenticated, how it is processed, and how it is displayed as output. In Physical design, the following requirements about the system are decided:

(a) Input requirement (b) Output requirements (c) Storage requirements (d) Processing Requirements (e)System control and backup or recovery

Put another way, the physical portion of systems design can generally be broken down into three sub-tasks:

(a) User Interface Design (b) Data Design (c) Process Design

User Interface Design is concerned with how users add information to the system and with how the system presents information back to them. Data Design is concerned with how the data is represented and stored within the system. Finally, Process Design is concerned with how data moves through the system, and with how and where it is validated, secured and/or transformed as it flows into, through and out of the system. At the end of the systems design phase, documentation describing the three sub-tasks is produced and made available for use in the next phase.

\subsection{Objectives of the design of the new system}

The main objective of the new system is to provide a user-friendly environment for GSM users in order to assist them in carrying out proper voice calls and data services, understand the reasons for poor system signals, delayed voice and data services and answer many other GSM unanswered questions that tend to mystify the system provision. By so doing, consumer goodwill is encouraged, market share grows, GSM remains afloat and economy is improved.

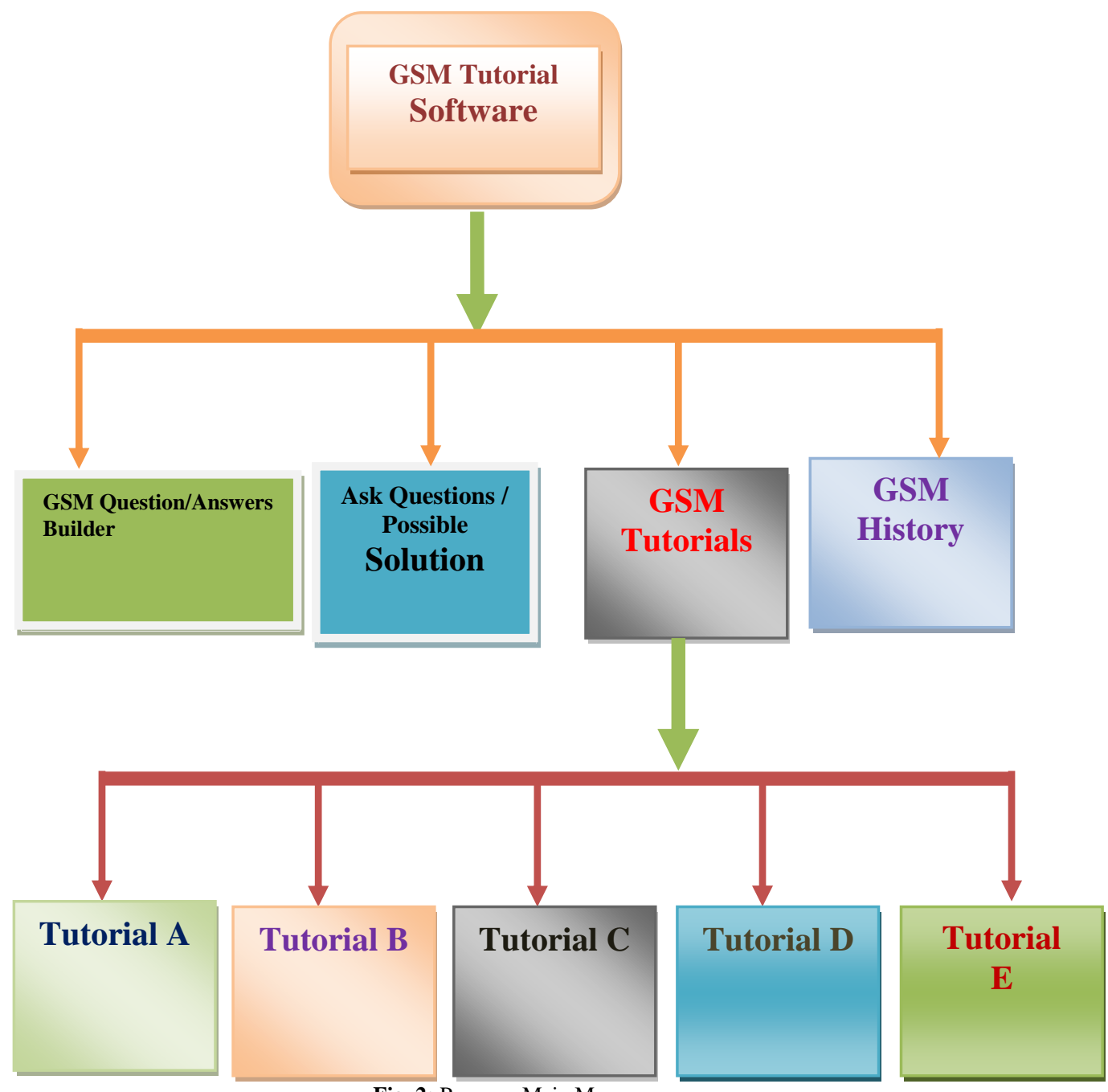

Fig. 2: Program Main Menu. 


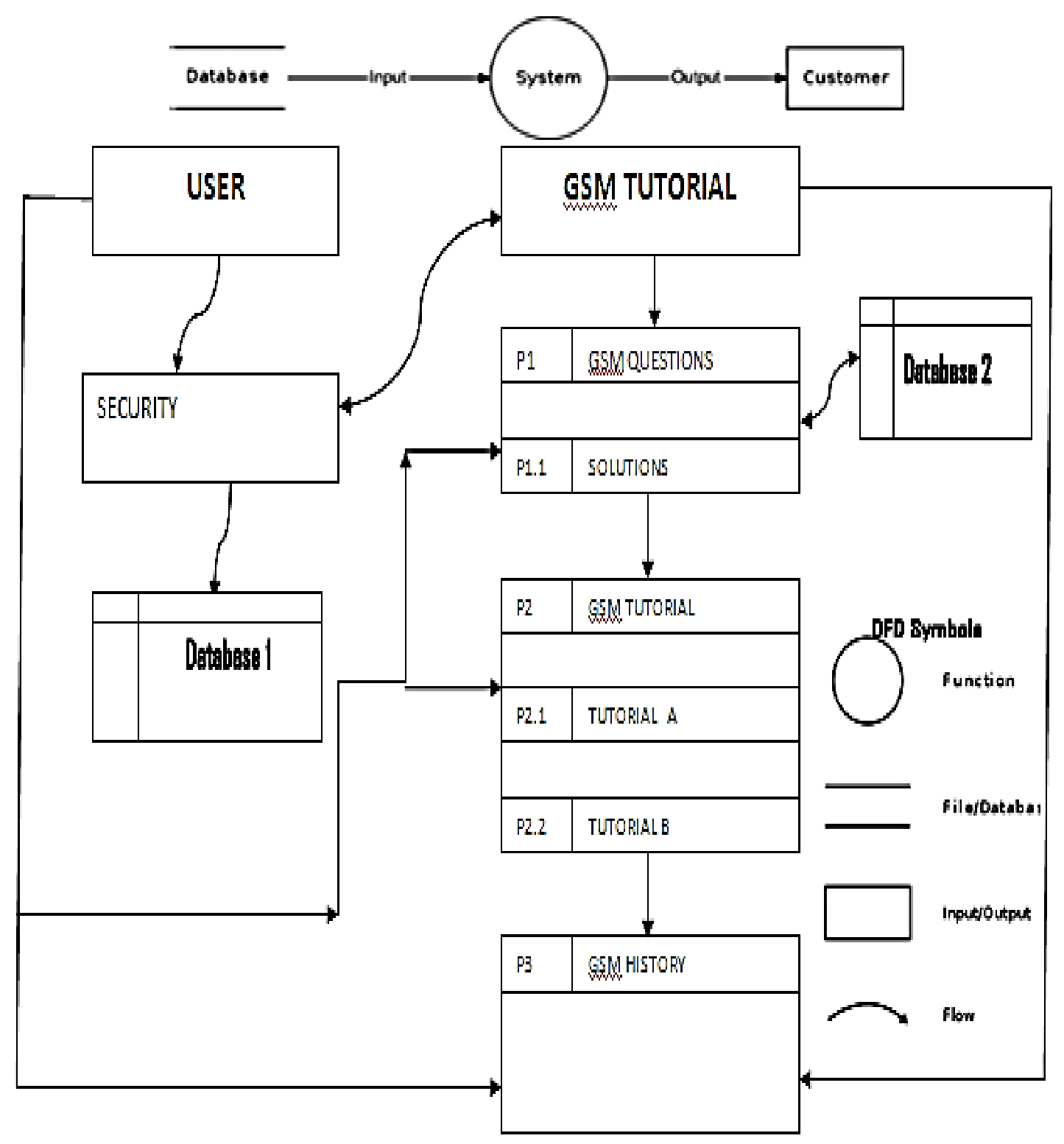

Fig. 3: Overall DFD of the New Program: Source [6]. 

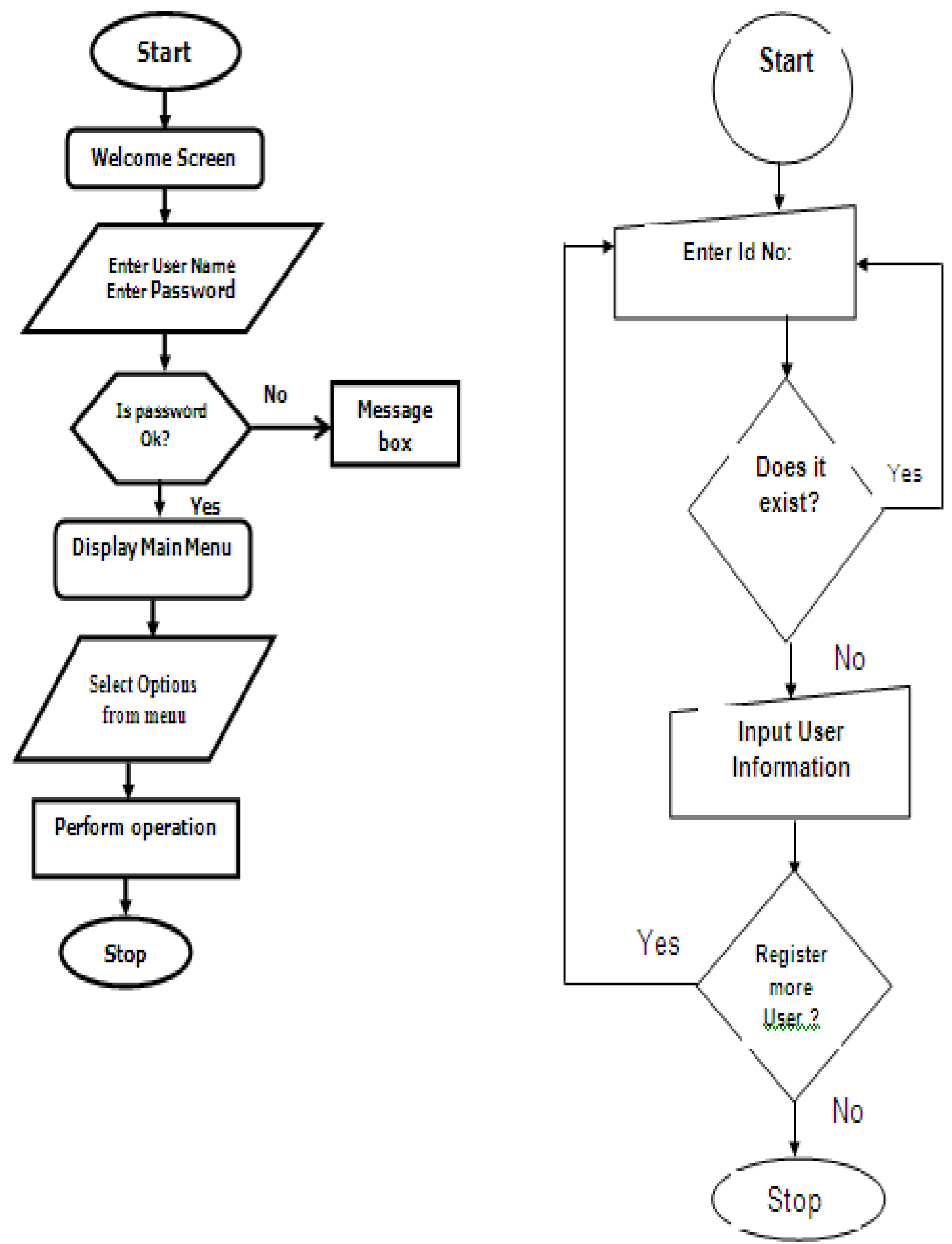

Fig. 4: Program Module Flowchart - Authentication Window Fig. 5: Program Module Flow Chart (User Registration) Source: [6] QUESTIONS/ANSWERS 


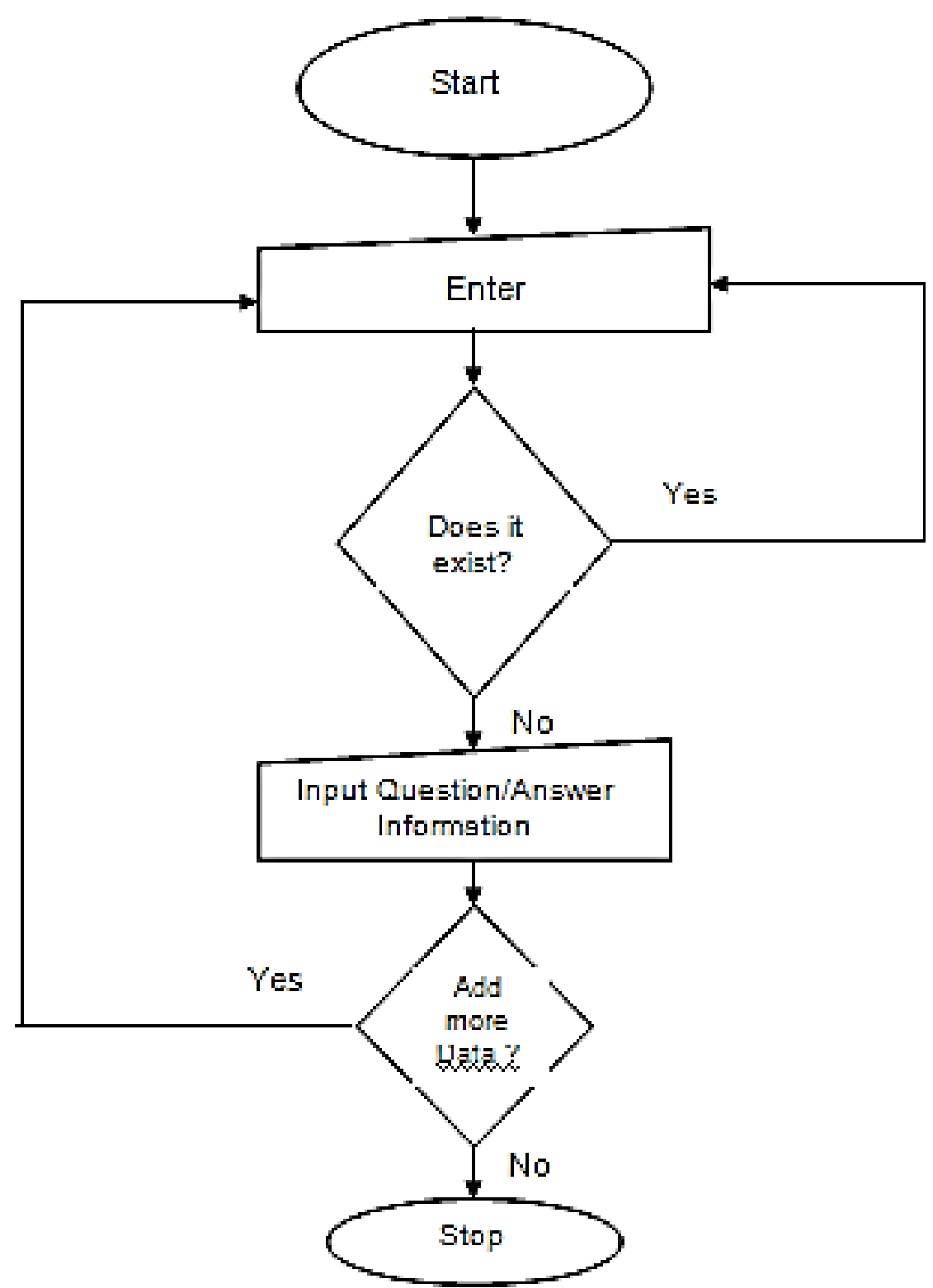

Fig. 6: Questions/Answers

\subsubsection{Testing and evaluation}

The Sample Population was a group of undergraduate students of computer science, Imo State University, Owerri numbering one hundred (100). Our sample test is the designed and developed intelligent based tutorial software to facilitate the maintenance of the GSM services. Both the tests and results are exemplified in the table 2 below.

The program was developed by using Visual Basic 6.0 and Microsoft Access. Visual Basic is an event-driven programming language with an Integrated Development Environment (IDE).

The project started by developing a database using MS-Access tables created and linked up to Visual Basic 6.0 environment, where forms and controls were created and codes were also written to direct them to perform required actions. Different kinds of tests were done: modular or elemental and performance testing. This was to verify specified requirements between expected and actual results. At the end, results were accurate, the program operated well as it performed tasks required of it. It achieved test goals for all inputs in addition to recognizing inputs outside its domain. In the process of doing this test, functionality, serviceability, performance, validation and verification as necessary performance and evaluation controls were considered.

The program was evaluated based on these set out criteria: Functionality, serviceability, ability, performance, validation and verification. 
Table 2: Probable Problems, Causes and Solution of the Present System

Problem Description
After restarting the
computer, there is no
signal indicated.

When the Device is being installed, the computer cannot find it.

1. You are in the place where there is no GSM/ GPRS /EDGE /WCDMA / HSDPA (HSUPA) network coverage. Such places include underground parking garages, tunnels, and some remote rural areas.

2. The device is not properly connected.

3. The SIM/USIM card isn't inserted properly.

4. The MODEM device is positioned in such a way as that adversely affects the devices signal reception.

1. The installation programs of the MODEM device have not been installed properly.

2. The device is not connected properly.

3. The SIM/USIM card is not inserted properly.

Sent Message failure.

1. The SMS center number is incorrect.

2. The network is busy or you are in an area with no signal.

1. You are in the place where there is no GSM/ GPRS/ EDGE/ WCDMA/ HSDPA (HSUPA) network coverage.

2. The network is busy.

3. The APN in the user configuration file is incorrect.

Data connection failed.
Problem Solving

1. Change location to find a good

Place where having signal.

2. Close the device safely as usual, pull out the device and reinsert the device again.

3. Remove and reinsert the SIM/USIM card correctly. 4. Adjust the angle / position of the MODEM device or its proximity to other electronic devices.

1. Run the installation program first then connect the device. Now install the drivers as normal in Windows.

2. Restart the computer, or reconnect the device.

3. Reinsert the SIM/USIM card correctly.

1. Your device is preconfigured so it is unlikely that it will need changing. However if it is missing or incorrect contact your operator.

2. Try later or move to an area with a stronger signal.

1. Move to an area with good signal.

2. Try later.

3. Check the APN in the user configuration file in the "Network settings".

4. Local network access or the target server maybe experiencing problems. Retry data request.

5. Reselect the network type according to the type of the SIM/USIM card. 
Program Outputs

Program Sample Input / Output
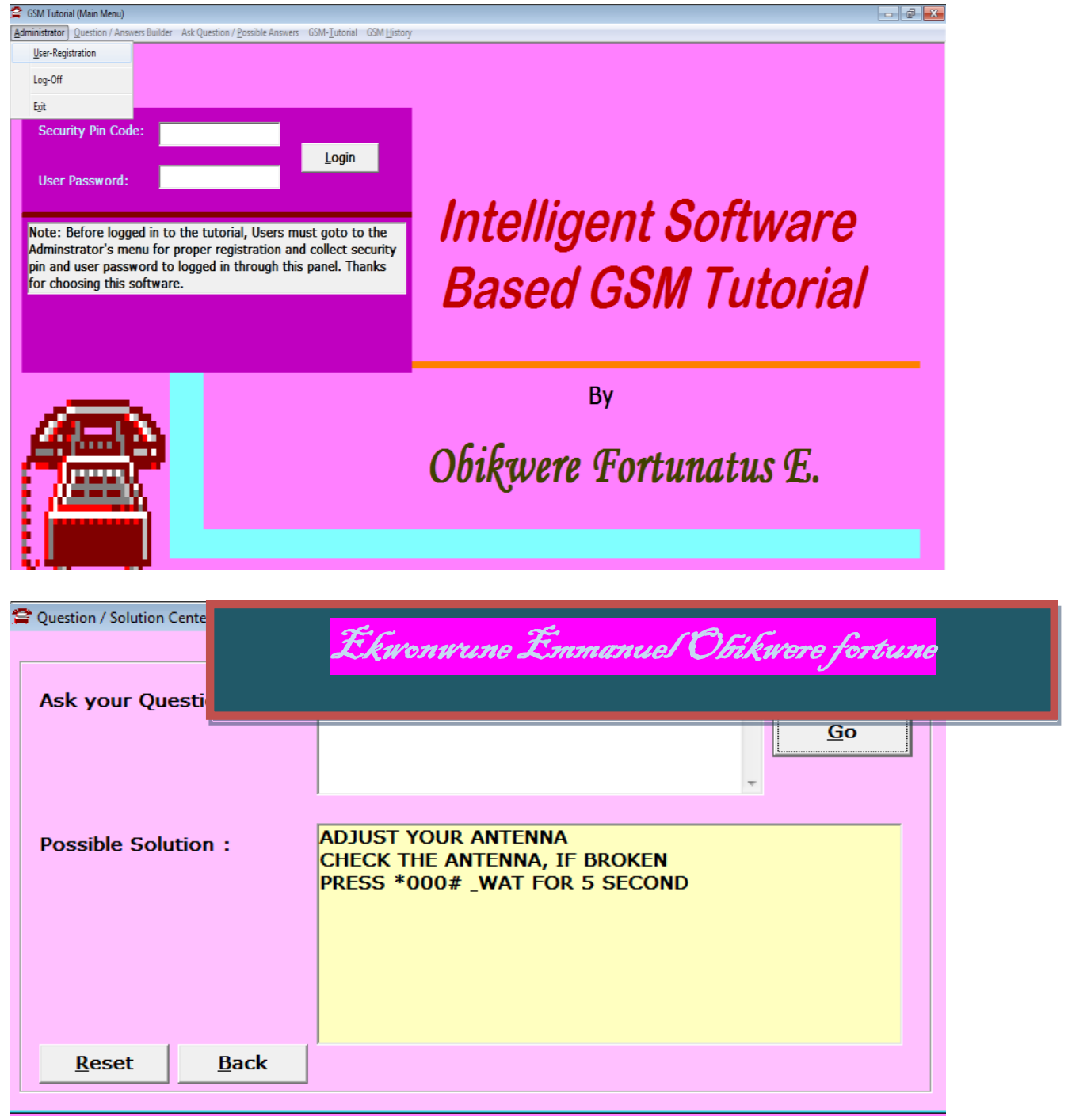

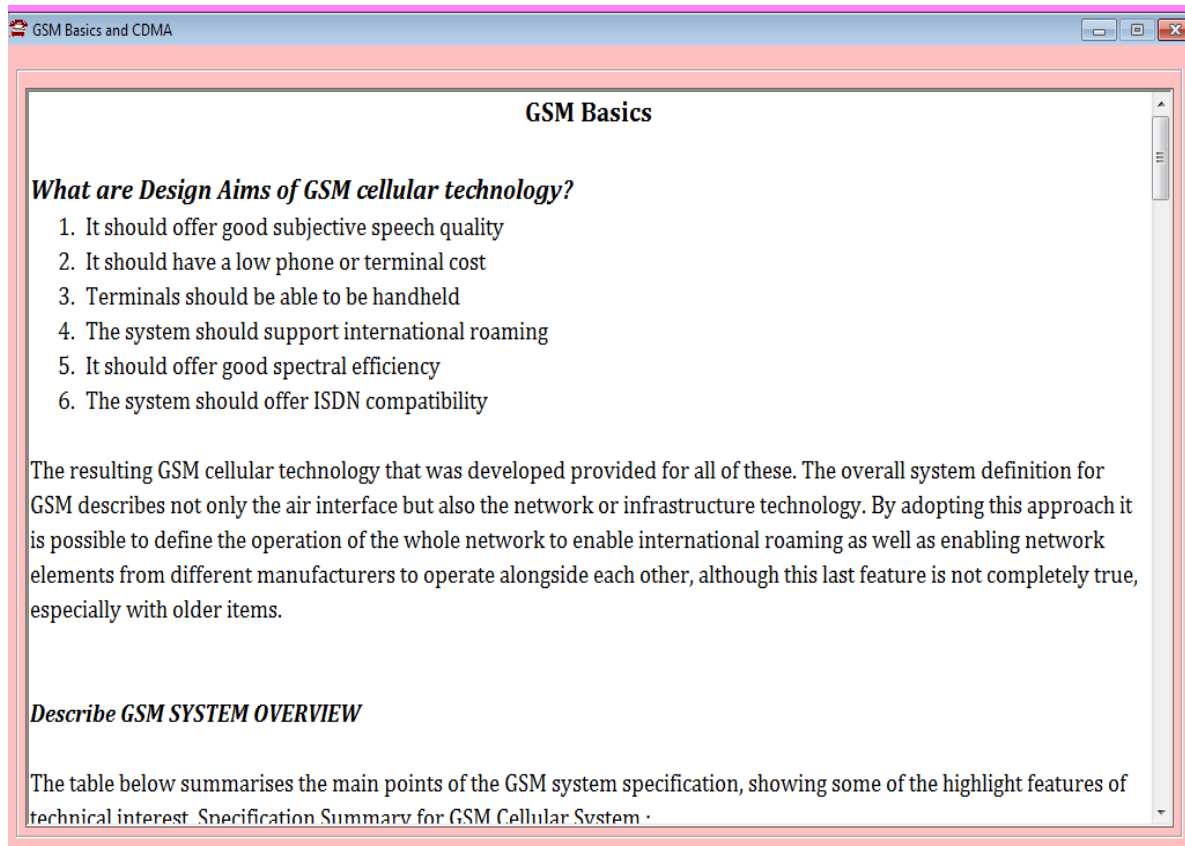




\section{Summary}

The study dealt with a proposal for a development of a GSM based intelligent software tutorial that would enhance the operations of the GSM communications in Nigeria with a view to adding values on its present state of operation for customer happiness. This is done when they could understand the reasons why certain things happen within the existing GSM network system. Descriptive research method, observations, survey questionnaires and interviews were brought to the fore in achieving set objectives. In developing the software, the following analytical tools were used: data flow diagram (DFD) and program flow chart (PFC). Method of software evaluation was used to prove its operational and technical feasibility of the proposed software. The technical feasibility was proved by using information regarding the hardware and software specifications, which includes the minimum and recommended requirements. The operational feasibility was proved under the criteria of accuracy, efficiency, reliability, security of use and user friendliness.

\section{Conclusion}

Expectations on GSM services are high. Thus, reliable, consistent, available, and affordable services are expected to be hallmark. However, it has been observed that the above expectations are not being wholly met. Some say that the GSM firms just exist but not achieving all the desired objectives yet, which means that there are problems peculiar to these all important communication infrastructures. Some of it challenges include: Lack of services signals, especially in the rural communities, Uncommitted but charged voice calls and data services leading to subscribers complaint of being shortchanged, over billing of subscribers through unsolicited promotional activities such as unsolicited messages for subscription of music, health tips, and reduced calls rate; Poor equipment in the likes of transponders, transmitters, modems, handsets; Operational costs - legal, overheads, statutory fees and Interferences by governments, individuals and groups, inter alia.

Nevertheless, there are Perceived bottlenecks to efficient operations of GSM services in Nigeria. They include: Political issues, Government policies, financial constraints and Low bandwidth due to poor equipment, among others. However, these encumbrances have taken their toll on the economy by way of look-warm interest in GSM consumption due to Poor services, complaints here and there; Poor subscription rate, Government loses revenue accruing from subscription tax and patronage, Goodwill diminishes - all resulting to a lower GDP.

Recommendation

The study recommends as follows:

- That the operators of GSM system wake up to their responsibilities to the GSM public by way of improving services through drop calls reduction to the barest minimum, making service signals available to both the rural and urban dwellers, reduced incidences of cross calls and adjustment of call rates to resemble those of developed economies of Europe, Asia and America.

- That federal government, which is the sole regulator of the GSM companies via National Communication Commission (NCC) should also wake up to its duties by ensuring close supervision of the works of these operators with a view to ensuring that they did their best towards giving the subscribers equal values for their money and to punish proportionately deviant ones among them based on established terms of contract.

- That government removes all the bottlenecks that inhibit the operations of GSM network in the country by providing such basic amenities like electricity, security, excess tariffs reduction and good roads, among others.

- $\quad$ That the GSM public gives its moral and financial support to the GSM infrastructure itself bearing in mind what they suffered when the networks were not there,

- $\quad$ That this proposed software leads to more organised, secure and better appreciation of the GSM networks with a view to making happy users of the system. Further to this is that the study would matter a lot to those doing further research in this area, where it will act as a reference material.

- That the work would create such a synergy between the users and operators such that would engender better subscription and good business to the operators and in that stead improve the national economy.

\section{References}

[1] http://www.telecomspace.com/gsm.html:TelecomSpace Tutorials, on: "GSM provides recommendations, not requirements" (2013)

[2] NCC: Subscriber Statistics : subscribers and teledensity for mobile and fixed telephony services on a monthly and

[3] http://www.gsma.com/gsm-technology in : "Mobile for Development Impact..." (2013)

[4] Bin Yang, Huicong Liu, Jingquan Liu and Chengkuo Lee (2014); Radioelectronics and Communications Systems.

[5] http://en.wikipedia.org/wiki/Nigerian_Communications_Commission

[6] F. Obichere (2013); Design and Development of Intelligent Electronic Tutorial Software for GSM Maintenance in Nigeria

[7] Microsoft @ Encarta ® 2008. (C) 1993-2007: Microsoft Corporation. 